\title{
Simulação de uma Unidade Piloto de Destilação de Água para uso em Laboratórios Químicos Empregando Energia Solar
}

\author{
Camila T. Damasceno, Gustavo R. Jordão \& Caridad N. Pérez
}

\begin{abstract}
No presente trabalho foi construído e modelado um destilador solar de água. O equipamento foi instalado no Instituto de Química da Universidade Federal de Goiás, em Goiânia (16 $46^{\circ}$ 'S $\left.49^{\circ} 15^{\prime} \mathrm{W}\right)$. A escolha do destilador solar se deve à alta incidência de irradiação solar no Brasil. Com os dados de irradiação solar e usando o modelo ambiental foi determinado que $20^{\circ}$ seria o melhor ângulo para a inclinação da cobertura do equipamento. Além disso, usando os dados de temperatura da água e da cobertura de hora em hora das 7 às 18, e o balanço de energia, proposto por Dunkle em 1961, foram calculados os coeficientes de transferência de calor, as taxas de transferência de calor e de massa e a eficiência do destilador para a cidade de Goiânia. Os resultados obtidos permitiram concluir que o coeficiente de transferência de calor de evaporação e sua taxa correspondente foram maiores do que os respectivos de convecção, a produção de água destilada no inverno e no verão foram de 0,31 e 1,51 kgm-2dia-1, respectivamente e a eficiência do destilador foi de 5,4\% no inverno e $41,33 \%$ no verão. A água obtida atende aos parâmetros da Farmacopeia Brasileira e pode ser usada nos laboratórios químicos em substituição à obtida nos destiladores elétricos.
\end{abstract}

Palavras chaves: Energia solar; destilação solar; água destilada.

In the present work was constructed and modeling a solar distiller water pilot installation. The equipment was installed in the Institute of Chemistry of the Federal University of Goiás, in Goiânia $\left(16^{\circ} 40^{\prime} \mathrm{S} 49^{\circ} 15^{\prime} \mathrm{W}\right)$. The choice of solar distiller is due to the high incidence of solar irradiation in Brazil. With the data of solar irradiation and using the environmental model it was determined that $20^{\circ}$ would be the best angle for the coverage inclination of the equipment. Besides that, using the temperature data of water and coverage, each hour from 7 to 18 , and the energy balance, proposed by Dunkle in 1961, the heat transfer coefficients, heat transfer, mass transfer rates, and the efficiency of the distiller were calculated. We conclude that the heat transfer coefficient of evaporation and its corresponding rate were higher than the respective convection, the production of distilled water in winter and summer were 0.31 and $1.51 \mathrm{kgm}-2$ day- 1 , respectively, and the efficiency of the distiller was $5,4 \%$ in the winter and $41,33 \%$ in the summer. The water obtained meets the parameters of the Brazilian Pharmacopoeia and can be used in chemical laboratories in substitution to that obtained in the electric distillers.

Keywords: Solar energy; Solar distillation; distilled water. 


\section{Introdução}

$\mathrm{O}$ acesso à água potável no planeta tem criado grandes problemas devido a sua escassez, principalmente em países em desenvolvimento. Aproximadamente $75 \%$ da crosta terrestre está coberta por água, dela 97,5\% encontra-se nos oceanos e $2,5 \%$ é água doce que se encontra na terra. Mesmo assim, somente $0,3 \%$ da água doce está ao alcance do homem e o restante está distribuída em glaciais, águas subterrâneas, rios, etc ${ }^{1,2}$.

A destilação solar de água é a única tecnologia que pode ser considerada renovável, devido a que usa a energia solar como fonte de energia. Uma unidade de destilação solar é ambientalmente aceitável, de fácil operação, de baixo custo de manutenção e fácil de instalar e de controlar. Além disso, a grande vantagem da destilação solar é que pode ser utilizada em qualquer lugar devido ao baixo custo de manutenção e à tecnologia simples ${ }^{3}$. A obtenção de água destilada por meio de energia solar foi experimentada no século IV a.C. por Aristóteles para evaporar água contaminada, que após condensação foi usada como água potável. Os primeiros trabalhos documentados sobre destilação solar datam do século XVI, onde os árabes produziam água potável por este método. Em 1589 Della Porrta usava vasos de barro expostos aos raios solares para a evaporação de água ${ }^{3}$.

Em 1872 foi instalado o primeiro destilador solar moderno em Las Salinas, Chile, para produzir água potável para os animais a partir de água salgada. Diversas unidades usando a mesma ideia, com variações geométricas, de materiais e formas de construção e de operação foram construídas depois ${ }^{4}$. No Egito foi instalada uma planta piloto para obter água doce a partir de água salgada préaquecida, antes de trocar o calor com o coletor solar ${ }^{5}$.

Destiladores em forma piramidal ou prisma triangular feitos em cloreto de vinilo foram testados para obtenção de água potável. A produção de água foi de 0,5 a 0,9 1/dia a um custo médio entre US \$ 0,046/1 e US \$ 0,063/16. Já no Chipre e na Turquia foram usados destiladores solares inclinados para produzir agua doce e quente simultaneamente para abastecimento doméstico7,8 e na Jordânia a destilação solar de água é usada para abastecer pequenas comunidades com água potável 9. Além disso, destiladores solares apresentaram também alta eficiência na remoção de mais de $99 \%$ dos contaminantes de das bactérias da água. Assim, destiladores solares de bacia única são capazes de produzir de água potável de alta qualidade a partir de água com alto grau de contaminação ${ }^{10}$.

A dessalinização da água de mar é um dos processos mais importantes para obter água potável. A destilação é o método mais prático e econômico, mas tem associado um alto custo energético devido à evaporação da água. Assim, a destilação solar torna-se atraente por causa do emprego da energia solar para a evaporação da água ${ }^{11}$. Já uma das desvantagens da destilação solar é que o tempo de recuperação do investimento varia de 2,1 a 4,6 anos, mas podem ser usados em países com alta incidência de raios solares $^{12}$.

Os destiladores solares de água são classificados em passivos e ativos. Nos destiladores ativos uma parcela extra de energia é fornecida na bacia de água, para aumentar a evaporação ${ }^{2,13,14,15,16}$. No caso do destilador passivo nenhum modo extra de energia é usado. Segundo Tiwari e col.14 os destiladores ativos produzem de 3 a 4 vezes mais do que os passivos. Outra desvantagem da destilação solar é sua baixa capacidade de produção. No caso dos destiladores solares passivos, a produção diária é, em média, de 1-3 kg/ $\mathrm{m}^{2} /$ dia, enquanto que nos destiladores solares ativos esse número sobe até cerca de $3-7 \mathrm{~kg} / \mathrm{m} 2 /$ dia. Devido à baixa produtividade por unidade de área, a tecnologia solar requer uma grande área de instalação para produzir grandes quantidades de água destilada ${ }^{14}$.

O princípio da destilação solar é uma transposição, em escala menor, do ciclo hidrológico da água, na qual a água da superfície terrestre se evapora pela ação da radiação solar se transformando em vapor, e a seguir, se acumula e condensa em contato com as camadas mais frias, originando as chuvas ${ }^{4}$. Assim, o funcionamento dos destiladores solares de água se baseia no princípio de evaporação e condensação. A água é alimentada em na unidade formando uma camada fina de água na bacia. A profundidade das bacias varia de 10-20 mm (rasas) e de 100 $\mathrm{mm}$ ou mais (profundas). A largura das bacias varia de 1 a 2 
m e o comprimento pode chegar a $100 \mathrm{~m} \mathrm{4,9}$. Tiwari e col. ${ }^{14}$ concluíram que o melhor rendimento de um destilador solar passivo se obtém com bacias rasas.

A radiação solar direta e difusa ao chegar à cobertura sofre reflexão, absorção e transmissão. Após ter sido refletida e absorvida na cobertura, a radiação solar, que foi transmitida pelo meio transparente, sofre reflexão na superfície da água, absorção na camada de água e reflexão e absorção no fundo da bacia. Assim, a água contida na bacia é aquecida e evaporada em condições de saturação no interior da unidade. Nem toda a energia refletida pela água é perdida, já que uma porção desta é novamente refletida pela superfície interior da cobertura. Uma fracção da energia solar absorvida pela cobertura é emitida para a água provocando, junto com a energia refletida o efeito de estufa, que possibilita o aquecimento da água a uma temperatura superior à da cobertura. A bacia de água troca calor com a cobertura por processos de transferência de calor por radiação, convecção natural e transferência simultânea de calor e massa por evaporação. Existe também perda de calor da água para o ambiente através de condução pela base e as paredes laterais da bacia. A água evaporada sobe por convecção natural até à cobertura onde é condensada na parte inferior. Uma vez condensada, a água flui por gravidade para os tanques de armazenamento localizados na extremidade inferior da cobertura. A quantidade de calor que chega à cobertura, proveniente da água, junto com a porção de energia solar absorvida pela cobertura é dissipada para a atmosfera por convecção e radiação ${ }^{4}$.

Dentre os parâmetros que afetam o desempenho dos destiladores solares estão a velocidade do vento, a radiação solar, a inclinação da cobertura e a temperatura ambiente ${ }^{2}$, a profundidade da bacia $^{17}$, o material de construção da superfície interna da cobertura18, a inclinação da cobertura, tipo de cobertura de uma ou duas pendentes e a estação do $a^{19}{ }^{19}$ e a presença ou não de tensoativos ${ }^{20}$. A diferença entre a temperatura da água, Tw, e da cobertura, Tg, é a força motriz para a transferência de calor e determina a produção de água. Para os destiladores solares passivos a única fonte de energia é a radiação solar, sendo esta sua principal desvantagem. Nos destiladores ativos, o fornecimento de energia térmica adicional permite aumentar a taxa de evaporação e como consequência a produtividade ${ }^{2}$.

A simulação, modelagem e validação dos modelos para diversos estudos de destilação solar de água faz uso de expressões com as temperaturas da água, Tw, e da cobertura, $\mathrm{Tg}$, para obter o rendimento horário e a eficiência de destiladores solares com cobertura de dupla inclinação. As análises se baseiam no balanço de energia do sistema. A faixa de temperatura de operação tem efeito significativo nos coeficientes internos de transferência de calor e o emprego da temperatura da cobertura interna, $\mathrm{Tg}$, conduziu a um bom ajuste entre os resultados teóricos e os experimentais. Assim, na modelagem térmica de destiladores solares devem ser empregados os dados de Tg para o cálculo dos coeficientes de transferência de calor ${ }^{19,21,22}$.

O rendimento e a eficiência térmica global horária de vários modelos de destiladores solares ativos foram avaliados e validados a diversas profundidas de água usando o modelo térmico do coletor de chapa plana integrado com a energia solar ativa e tubo de aquecimento evacuado ${ }^{22}$.

A associação Brasileira de Indústria Elétrica e Eletrônica publicou na sua página na internet que os valores máximos de irradiação solar são observados na parte oeste da região Nordestina, que inclui parcialmente o norte de Minas Gerais, o nordeste de Goiás e o sul de Tocantins. Assim como na região Norte, a região Centro-Oeste do Brasil recebe a maior incidência de radiação solar durante o período de seca, entre os meses de julho e setembro, período de céu claro e poucas precipitações ${ }^{23}$.

O objetivo principal do presente trabalho foi $o$ dimensionamento de uma unidade piloto de destilação solar de água para ser instalada no Instituto de Química da Universidade Federal de Goiás (IQ-UFG). Outro objetivo foi a modelagem e validação do destilador fazendo uso do modelo de Dunkle simplificado, para a avaliação dos coeficientes e das taxas de transferência de calor por convecção e por evaporação, da massa de água produzida e da eficiência do destilador solar. Além disso, com a água destilada coletada no equipamento fazer a análise química para avaliar se a água obtida poderia substituir a água destilada dos destiladores elétricos. 


\section{Metodologia Experimental}

\section{MODELO AMBIENTAL E BALANÇO DE ENERGIA}

O cálculo da radiação incidente no plano inclinado da superfície do destilador pela determinação da geometria solar e da variável tempo solar foi realizado usando o modelo ambiental desenvolvido por Duffie e Beckman ${ }^{24}$. Com a radiação incidente foi possível analisar a composição e variação da radiação na cidade de Goiânia e predizer o ângulo ideal para a construção do equipamento. Já, os coeficientes de transferência de calor por convecção e evaporação, as taxas de transferência de calor, a produção horária de água destilada e o rendimento de destilador foram obtidos usando modelo de Dunkle ${ }^{25}$ para o balanço de energia no destilador solar. As Tabelas 1 e 2 apresentam as variáveis de entrada de ambos os modelos.

Tabela 1. Variáveis de entrada do modelo ambiental de Duffie e Beckman ${ }^{24}$

\begin{tabular}{|c|c|}
\hline Variável & Unidade \\
\hline Altitude & km \\
\hline Longitude & 0 \\
\hline Latitude & 0 \\
\hline Meridiano Local & - \\
\hline Dia do ano (n) & - \\
\hline Albeto & 0 \\
\hline Inclinação da superfície & - \\
\hline Fatores de correção para o clima tropical \\
\hline r0 & - \\
\hline r1 & - \\
\hline K & \\
\hline
\end{tabular}

Tabela 2. Variáveis de entrada do modelo de Dunkle25 para o balanço de energia

\begin{tabular}{|c|c|}
\hline Variável & Unidade \\
\hline $\begin{array}{c}\text { Temperatura da } \\
\text { cobertura,Tg }\end{array}$ & oC \\
\hline Temperatura da água, Tw & oC \\
\hline $\begin{array}{c}\text { Calor latente de vaporização } \\
\text { Radiação horária no plano } \\
\text { inclinado }\end{array}$ & $\mathrm{J} / \mathrm{kg}$ \\
\hline (It) & $\mathrm{W} / \mathrm{m} 2$ \\
\hline
\end{tabular}

\section{CONSTRUCCÃO DO DESTILADOR SOLAR}

$\mathrm{O}$ destilador foi construído em vidro comum de 3 $\mathrm{mm}$ de espessura, com um ângulo de $20^{\circ}$ de inclinação da cobertura e as medidas da bacia de água foram de $0,6 \times 0,8 \times 0,1 \mathrm{~m}$ (comprimento $\mathrm{x}$ largura $\mathrm{x}$ altura). Vidros de menor espessura permitem obter maior produção de água do que vidros com espessuras maiores 26 . O equipamento foi instalado entre os prédios I e II do Instituto de Química da Universidade Federal de goiás - Campus Samambaia, na cidade de Goiânia, latitude $-16^{\circ} 40^{\prime} 43$ '. O destilador solar. Na Figura 1 se apresenta o esquema de montagem do destilador solar, a peça que forma a vista do perfil do equipamento é a única que não tem formato retangular, as outras são retângulos de $0,1 \times 0,8 \mathrm{~m}$ utilizados para ligação entre a vista frontal e a posterior do aparato. Além disso, no fundo foi utilizado uma peça de $0,6 \times 0,8 \mathrm{~m}$ e nas coberturas, duas peças de $0,48 \times 0,85 \mathrm{~m}$. 


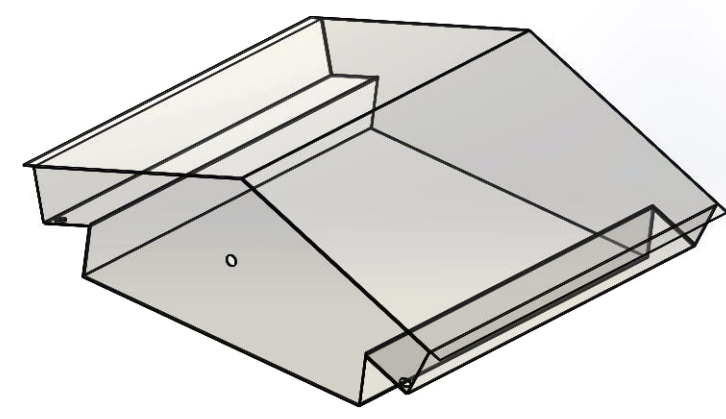

Figura 1. Esquema de montagem do destilador solar

A cobertura do destilador foi fixada com silicone à parte inferior do equipamento. No fundo da bacia que armazena água bruta foi colocada uma placa de alumínio revestida com tinta preta fosca, a fim de aumentar a absorção de energia. Um barril conectado ao destilador armazena água para manutenção do nível de água a ser destilada. Galões conectados às canaletas armazenam o destilado de ambos os lados do equipamento. O destilador foi colocado sob um suporte com tampo de madeira para que houvesse isolamento térmico. As coletas de temperatura da água e da cobertura foram realizadas entre 18/05/2016 e 07/07/2016, no inverno; e entre 20/10/2016 e 10/11/2016, no verão. Termopares do tipo $\mathrm{K}$ calibrados foram utilizados para registro das temperaturas da água na bacia, no teto de vidro e da temperatura ambiente. Os dados foram colhidos de hora em hora, das 8 às $18 \mathrm{~h}$ de cada dia.

\section{ANÁLISE DAS AMOSTRAS DE ÁGUA COLETADAS}

Amostras de água foram coletadas ao final de cada dia, armazenadas em recipiente hermeticamente fechado e refrigeradas para posterior análise de condutividade. $\mathrm{O}$ condutivímetro Schot t, modelo CG 853 foi empregado para fazer as medidas de condutividade da água coletada. Lavou-se o eletrodo com água Milli-Q e calibrou-se com solução de $\mathrm{KCl}$ de referência na concentração de $0,01 \mathrm{M}$, em seguida prosseguiu-se com as medidas de condutividade das coletas de água destilada, tomando o devido cuidado de lavar o eletrodo com água Milli-Q sempre que houvesse a troca da amostra.

\section{BALANÇO DE ENERGIA}

O modelo para o balanço de energia desenvolvido por Dunkle25 para sistema de destilação solar foi usado para avaliar os coeficientes e as taxas de transferência de calor por convecção e por evaporação, assim como a taxa horária de água destilada produzida. De acordo com a lei da conservação de energia: a energia acumulada é igual à diferença entre a quantidade de energia que entra e que sai do volume de controle.

$$
q_{\text {entra }}-q_{\text {sai }}=m_{w} \cdot L_{w} \cdot \frac{\partial T}{\partial t}
$$

Adotando um ponto de água na bacia como volume de controle tem-se:

$$
\alpha \cdot \tau_{c} \cdot I_{g}=q_{e}+q_{r, w-g}+q_{c, w-g}+q_{k}+(m L)_{w} \frac{\partial T}{\partial t}
$$

Os subscritos e, r, c, k, w e g referem-se à evaporação, radiação, convecção, condução, água da bacia e cobertura, respectivamente. $\mathrm{O}$ termo $\tau_{c}$ representa a transmitância no vidro, $\alpha$ é a absortividade no vidro, $I_{g}$ é a radiação que entra na cobertura $\left(\mathrm{W} / \mathrm{m}^{2}\right), L_{w}$ é o calor latente de vaporização $(\mathrm{J} / \mathrm{kg})$. A partir das definições de taxa de transferência de calor por convecção entre a água e a cobertura e a taxa de transferência de calor por radiação entre a cobertura e o ambiente, obtém-se a seguinte equação:

$$
\alpha \cdot \tau_{c} \cdot I_{g} \cdot A_{g}+h_{t w} \cdot A_{w}\left(T_{w}-T_{c}\right)=m_{w} \cdot L_{w} \frac{\partial T}{\partial t}+h_{1 g} \cdot A_{g}\left(T_{g}-T_{a}\right)
$$

Onde Ag é a área da cobertura $\left(\mathrm{m}^{2}\right)$; Aw é a área da camada de água na bacia $\left(\mathrm{m}^{2}\right)$; htw é o coeficiente total de transferência de calor da água para a cobertura (W/ $\mathrm{m}^{2} \mathrm{oC}$ ). Tw é a temperatura da água oC; $\mathbf{T g}$ é a temperatura da cobertura oC. Ta é a temperatura ambiente oC. h1g é o 
coeficiente de transferência de calor convectivo e radiativo da cobertura para o meio ambiente $(\mathrm{W} / \mathrm{m} 2$. oC); mw é a taxa de condensação $(\mathrm{kg} / \mathrm{h})$.

O coeficiente total de transferência de calor da água para a cobertura $\left(h_{t w}\right)$ é a soma dos coeficientes de convecção $\left(h_{c w}\right)$, radiação $\left(h_{r w}\right)$ e evaporação $\left(h_{e w}\right)$. A transferência de calor e de massa num destilador ocorre simultaneamente, sendo assim, Dunkle25 sugeriu uma modificação no número de Rayleigh considerando os efeitos da flutuação (empuxo) devido às variações de densidade e ao gradiente de temperatura. Assim, na equação

$$
\mathrm{Ra}=\frac{g \cdot \beta \cdot \Delta T \cdot L^{3} \cdot \rho^{2} C_{p}}{\mu \cdot k}
$$

o número de Rayleigh passa a ter uma diferença de temperatura equivalente, levando em conta as diferenças de densidade no vapor de água, dado pela Equação 4.

$$
\Delta T=\left(T_{w}-T_{g}\right)+\frac{T_{w}\left(P_{w}-P_{g}\right)}{268,9 \cdot 10^{3}-P_{w}}
$$

Onde Tw é a temperatura da água (K); $\mathbf{T g}$ é a temperatura da cobertura $(\mathrm{K})$; Pw é a pressão parcial de vapor da água em função da temperatura Tw $(\mathrm{Pa})$; Pg é a pressão parcial de vapor da água em função de $\mathrm{Tg}(\mathrm{Pa})$. Em que $\mathrm{Pw}$ e $\mathrm{Pg}$ são calculadas pelas Equações 5 e 6.0 termo $T_{w}+273$ e $T_{g}$ +273 é a conversão da temperatura em graus Celsius para temperatura absoluta.

$$
\begin{aligned}
& P_{w}=\exp \left[25,317-\left(\frac{5144}{T_{w}+273}\right)\right] \\
& P_{g}=\exp \left[25,317-\left(\frac{5144}{T_{g}+273}\right)\right]
\end{aligned}
$$

Substituindo-se Rayleigh na equação do número de Nusselt:

$$
N u=\frac{h_{c w} \cdot L}{k}=0,075 \cdot\left(\frac{g \cdot \beta \cdot \Delta T \cdot L^{3} \cdot \rho^{2} C_{p}}{\mu \cdot k}\right)^{\frac{1}{3}}
$$

A partir da equação anterior, e adotando parâmetros físicos aplicáveis na gama de funcionamento de um destilador, Dunkle25 obteve a relação:

$$
h_{c w}=0,884\left[\left(T_{w}-T_{g}\right)+\frac{\left(P_{w}-P_{g}\right)\left(T_{w}+273\right)}{268,9 \cdot 10^{3}-P_{w}}\right]^{\frac{1}{3}}
$$

Em que as pressões são dadas em $\mathrm{Pa}$, e as temperaturas em graus Celsius. A taxa de transferência de calor por convecção é dada pela Equação 8:

$$
q_{c w}=h_{c w} \cdot\left(P_{w}-P_{g}\right)
$$

O coeficiente evaporativo, hew, e o calor transferido por unidade de área e tempo por evaporação, qew, podem ser calculados a partir das Equações 9 e 10. 


$$
h_{e w}=0,016273 . h_{c w} \cdot \frac{P_{w}-P_{g}}{T_{w}-T_{g}}
$$

$$
q_{e w}=h_{e w}\left(T_{w}-T_{c}\right)
$$

Desse modo, sendo Lw o calor latente de vaporização $(\mathrm{J} / \mathrm{kg})$, a taxa de transferência de massa pode ser obtida por:

$$
\dot{m}_{e w}=\frac{q_{e w}}{L_{w}}
$$

A eficiência do equipamento de destilação pode então ser obtida através da taxa de transferência de calor por evaporação (qew), e da radiação horária incidente na superfície do destilador (It) de acordo com a Equação 10.

$$
\eta_{i}=\frac{q_{e w}}{I_{t}} \times 100
$$

\section{Resultados e Discussão}

\section{MODELO AMBIENTAL}

O estudo da radiação solar na cidade de Goiânia, onde está o maior campus da Universidade Federal de Goiás, foi realizado usando o modelo ambiental ${ }^{24}$. Na Figura 2 se apresentam os resultados da radiação total no plano horizontal (Ih) - e suas componentes direta (Id) e difusa (Ib) para a cidade de Goiânia (latitude $-16^{\circ} 40^{\prime} 43^{\prime \prime}$ ) no Estado de Goiás, Brasil - durante as 24 horas dos dias 21 de junho (solstício de inverno) e 21 de dezembro (solstício de verão). O clima de Goiás é predominantemente tropical com duas estações bem definidas: verão úmido e inverno seco. Os solstícios foram escolhidos por caracterizarem o início das duas estações características.

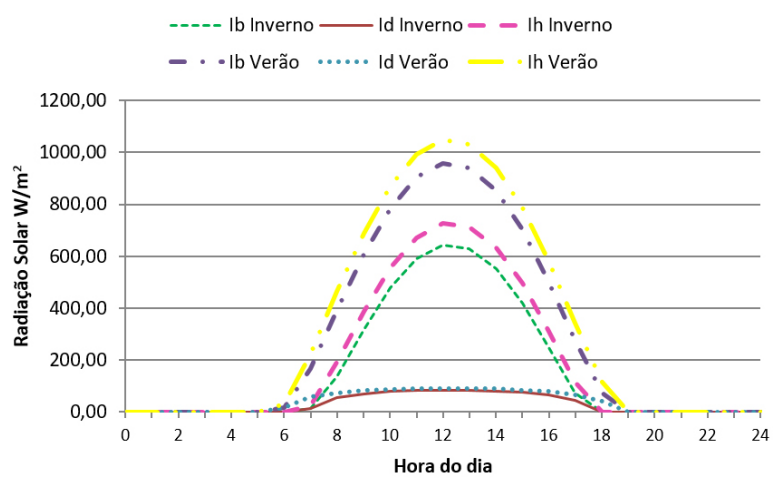

Figura 2. Radiação no plano horizontal total, e suas componentes direta e difusa, para os solstícios de inverno e verão em Goiânia.

Da Figura 2 é possível afirmar que a radiação total no verão é sempre maior que no inverno, porém, não há grandes diferenças na radiação total, havendo por tanto uma boa disponibilidade deste recurso nas duas estações. Como a radiação difusa sofre pequena alteração, a maior parcela da radiação total é referente à radiação direta. Os valores da radiação obtidos no inverno e verão para a cidade de Goiânia foram bem próximos, assim como o número de horas de sol como mostrado na Figura 3.

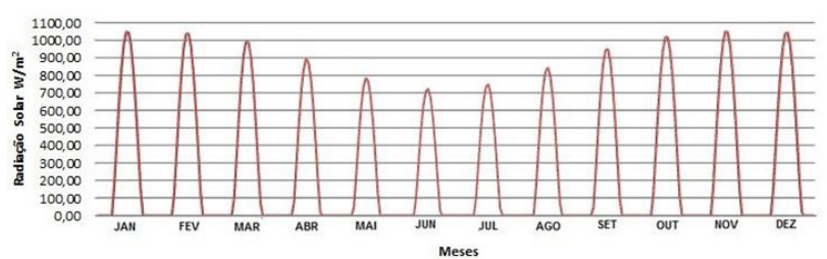

Figura 3. Radiação no plano horizontal média mensal para a cidade de Goiânia.

Na Figura 3 evidencia-se a variação da radiação solar incidente numa superfície horizontal ao longo de um dia de cada mês do ano para a cidade de Goiânia. O 
comportamento observado é característico de clima Tropical, em que há uma redução nos meses de inverno e aumento nos meses de verão, porém, em ambas as estações, a radiação total incidente é alta tornando a cidade propícia para a instalação do destilador solar. Para determinar o melhor ângulo de inclinação da cobertura do destilador, foi feita uma simulação para obter a variação da radiação incidente numa superfície inclinada nos solstícios de inverno e de verão para a cidade em função do ângulo de inclinação da cobertura. Nessa simulação foram usados os ângulos de 5o, 15o, 25o, 35o e 55o para Goiânia nos solstícios de inverno e verão, e os resultados desta simulação são apresentados nas Figura 4 e 5.

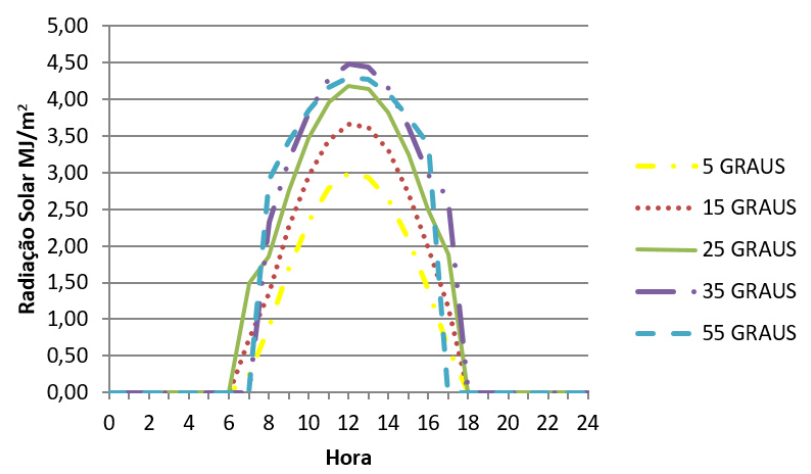

Figura 4. Radiação incidente numa superfície inclinada no solstício de inverno para a cidade de Goiânia

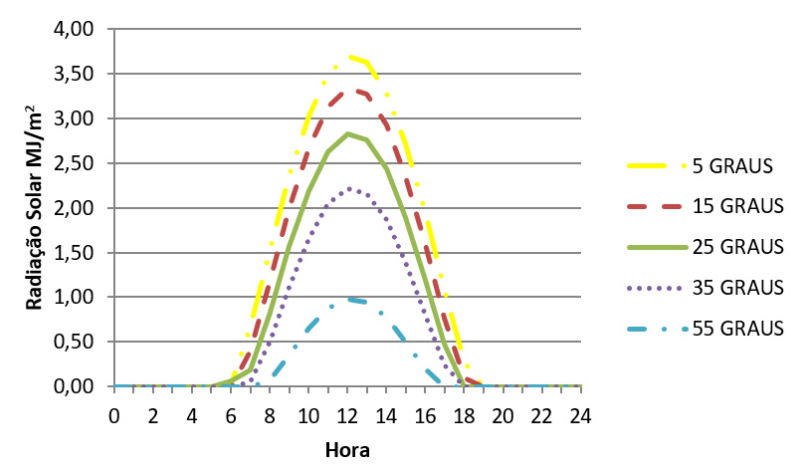

Figura 5. Radiação incidente numa superfície inclinada no solstício de verão para a cidade de Goiânia.
Dos resultados apresentados nas figuras anteriores observa-se que para o inverno, na cidade de Goiânia o a cobertura com ângulo de inclinação igual a 350 recebe a maior incidência de radiação. Enquanto que no verão a radiação foi maior nas inclinações mais baixas, sobretudo o ângulo de 5o proporcionou a maior incidência de energia. Resultados similares foram obtidos por Jorge27 e Singh e Tiwari28. Sendo assim, para o projeto do destilador solar, tornou-se necessário definir o ângulo ótimo em que será possível coletar o maior índice de energia durante todo o ano. A Figura 6 foi construída a partir da média anual de radiação incidente numa superfície inclinada para cada ângulo estudado para a cidade de Goiânia.

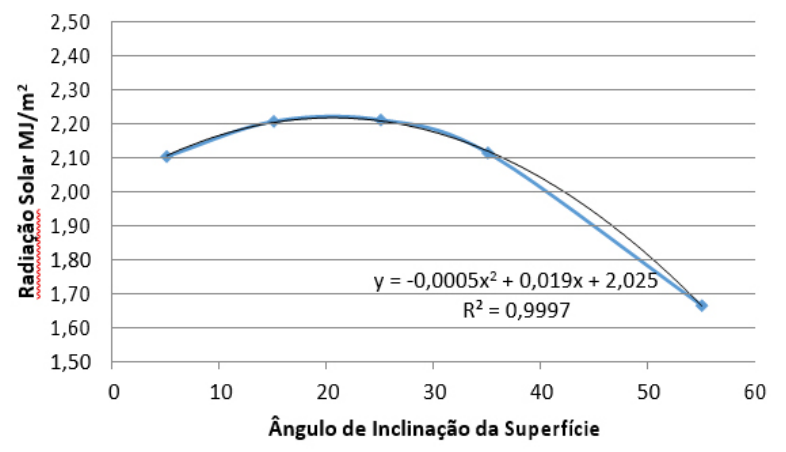

Figura 6. Influência da inclinação da superfície na radiação média anual para a cidade de Goiânia.

O ponto máximo da curva da radiação foi obtido para um ângulo de inclinação da superfície de 19,00 em Goiânia. O ângulo óptimo obtido está próximo ao ângulo da latitude da cidade em estudo $-16^{\circ} 40^{\prime} 43$ '. Segundo Singh e Tiwari28, com o ângulo de inclinação da cobertura semelhante ao ângulo de latitude, os raios solares incidirão de forma normal à superfície durante todo o ano. O ângulo encontrado no modelo ambiental está próximo de $20^{\circ}$, e próximo do ângulo da latitude da cidade de Goiânia, por isso foi escolhido este ângulo, 20o, para a inclinação da cobertura e foi usado no desenho e construção do destilador.

A Figura 7 representa a radiação solar incidente num plano inclinado (It) para o ângulo de inclinação da cobertura 
de $20^{\circ}$ na cidade de Goiânia ao longo dos dias 20/05/2016 e 27/10/2016 - datas em que foram realizadas coletas de temperatura no equipamento de destilação. A radiação obtida permitiu, através do modelo de balanço de energia, calcular a eficiência do destilador.

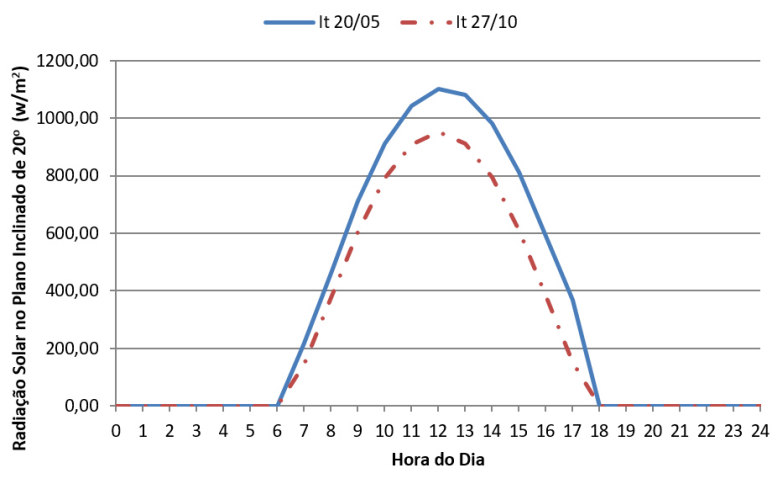

Figura 7. Radiação solar incidente no plano inclinado de $20^{\circ}$ na cidade de Goiânia ao longo dos dias 20/05/2016 e 27/10/2016.

\section{CONSTRUÇÃO DO DESTILADOR SOLAR}

O equipamento construído em vidro comum de $3 \mathrm{~mm}$ de espessura, possui dimensões de $0,6 \mathrm{~m} \times 0,8 \mathrm{~m}(0,48$ $\mathrm{m} 2$ de área da bacia), com $0,14 \mathrm{~m}$ de altura, e espaço entre a superfície da bacia e o topo medindo $0,60 \mathrm{~m}$, conforme representado no desenho apresentado no material suplementar. A instalação foi feita com o maior comprimento no sentido leste-oeste. De acordo com Pina29, o tamanho ideal para destiladores de pequeno porte está entre 80 e 90 $\mathrm{cm}$, e segundo Bezerra30, as faces dos destiladores de duas águas devem estar voltadas para a nascente e poente de modo favorecer a incidência dos raios solares. A cobertura foi construída com design de duas águas, formada por duas placas de vidro de $0,48 \mathrm{~m}$ x $0,85 \mathrm{~m}$ com ângulo de inclinação de $20^{\circ}$. Segundo Murugavel e col. 31, este é o modelo ideal para locais em que a latitude é inferior à $20 \mathrm{o}$. A Figura 8 a seguir mostra uma fotografia do equipamento construído e utilizado para os testes.

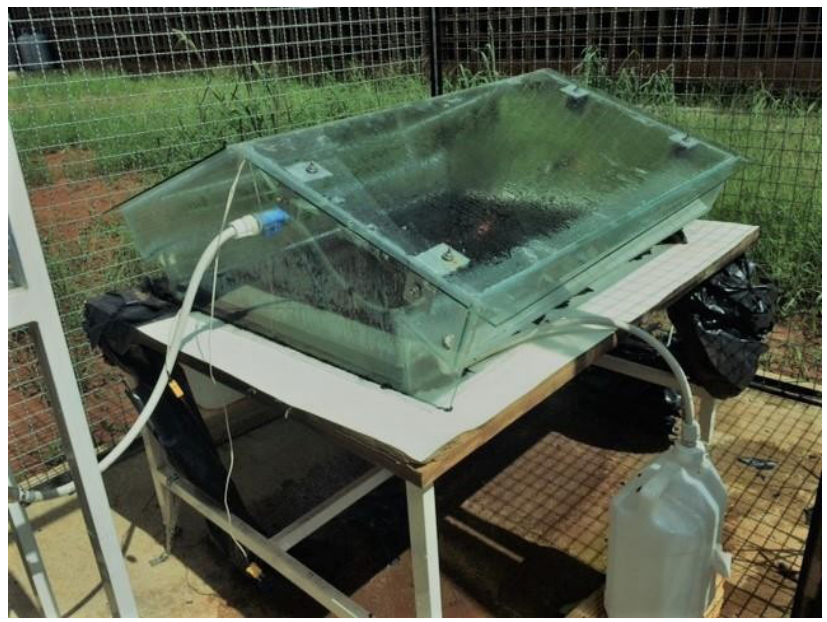

Figura 8. Fotografia da unidade piloto de destilação solar de água (Camila T. Damasceno) Coleta de temperatura da água e da cobertura no verão e no inverno.

As temperaturas foram registradas em todos os dias de análises e, para efeito dos cálculos subsequentes, considerou-se um dia característico do inverno (20/05/2016) e outro no verão (27/10/2016). As Figuras 9 e 10 mostram os valores de temperatura da água da bacia $(\mathrm{Tw})$ e da parte inferior da cobertura $(\mathrm{Tg})$, de hora em hora das $8 \mathrm{~h}$ às $18 \mathrm{~h}$ de cada dia.

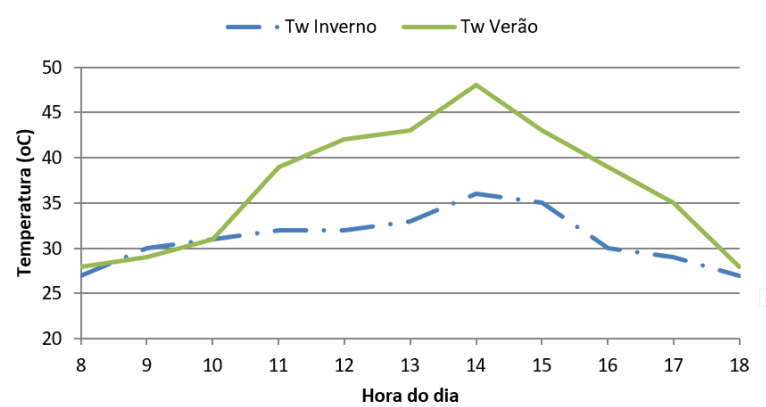

Figura 9. Temperatura da água (Tw) versus hora em dias característicos do inverno e do verão. 


\section{Artigo Convidado 1}

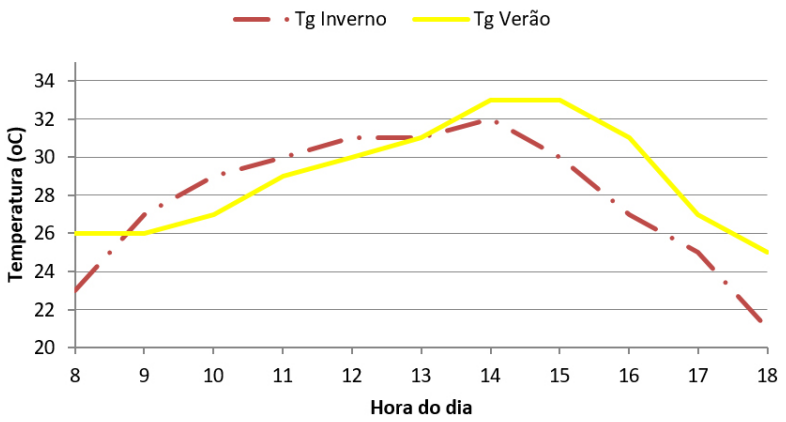

Figura 10. Temperatura interna da cobertura $(\mathrm{Tg})$ versus hora em dias característicos do inverno e do verão.

Nas primeiras horas do dia as temperaturas da água na bacia (Tw) no inverno e no verão apresentaram uma diferença de apenas um grau. Porém, observou-se que no verão acontecia um grande acréscimo na temperatura da água no período das $10 \mathrm{~h}$ às $18 \mathrm{~h}$, quando a intensidade da radiação solar é maior. A variação das temperaturas da água nos dois dias foi de $1 \mathrm{oC}$ à $12 \mathrm{oC}$. Porém, a temperatura da cobertura $\left(\mathrm{T}_{\mathrm{g}}\right)$ pouco se alterou se comparado um dia de inverno com um dia de verão, onde a variação máxima foi de $4^{\circ}$.

Isso se deve ao fato da temperatura ambiente $\left(T_{a}\right)$, que influencia diretamente a temperatura da cobertura, não ter se alterado significativamente nos dois dias em estudo, conforme Figura 11.

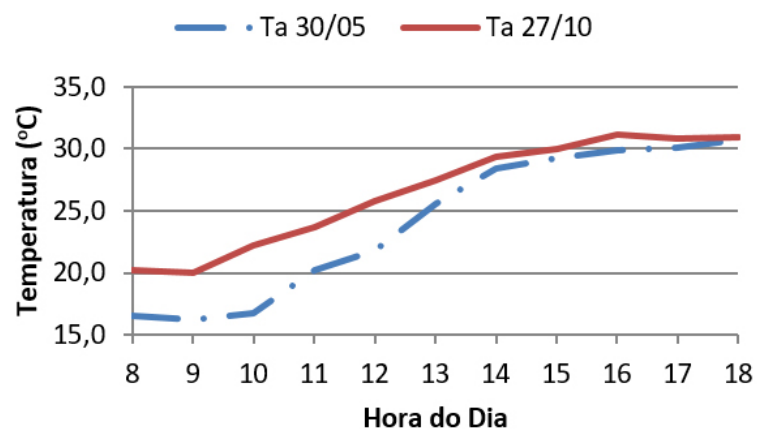

Figura 11. Variação da temperatura ambiente dos dias 30/05/2016 e 27/10/2016 para a cidade de Goiânia, segundo estação meteorológica Fonte de dados: Instituto Nacional de Meteorologia - INMET ${ }^{32}$.
Os resultados da diferença de temperatura entre a água e a parte interna da cobertura são mostrados na Figura 12. Sendo que esta diferença é a força motriz para a transferência de calor dentro do destilador, promove a circulação por convecção, possibilita o fluxo do fluido e a condensação posterior do vapor de água no topo do equipamento. Assim, quanto maior seja essa diferença de temperatura, maior será a produção de água destilada.

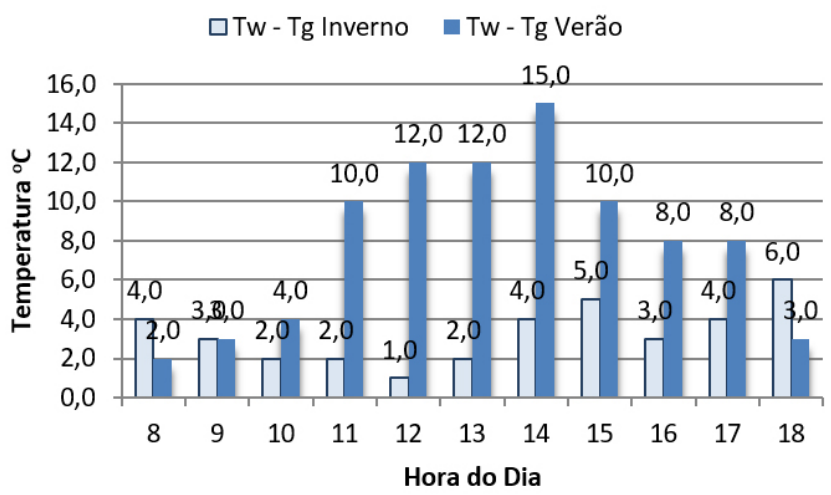

Figura 12. Diferença de temperatura entre a cobertura do destilador e a superfície da água na bacia em um dia característico de inverno e verão.

Dimri $^{33}$ avaliou o efeito da diferença de temperatura entre a cobertura e a água na bacia de um destilador projetado para Nova Deli, e observou um rendimento maior do equipamento quando foi fornecida energia extra à água na bacia, devido a maior diferença de temperatura. Para um dia de verão observou que a diferença de temperatura aumentava até às $14 \mathrm{~h}$ e chegou a $15 \mathrm{o}$, tendo a seguir uma diminuição da diferença de temperatura nas horas posteriores. Além disso, a dependência da temperatura da água na bacia também depende da intensidade da radiação incidente. Na coleta dos dados do presente trabalho, as 
menores diferenças de temperatura foram registradas nas primeiras horas do dia, o que poderia ser atribuído à perda da energia acumulada na massa de água durante a noite. A diminuição da diferença de temperatura na última hora de análise, pode ser devido à que nessas horas a radiação incidente na cobertura do destilador diminui consideravelmente. No inverno ocorre que a diferença de temperatura entre Tw e Tg é menor ao longo do dia devido à dois fatores: a temperatura baixa da água (consequência da menor radiação incidente), e a temperatura ambiente bem próxima da que se obtém no dia de verão.

\section{Balanço de Energia}

Com as temperaturas da cobertura $(\mathrm{Tg})$ e da água na bacia (Tw), coletadas durante os experimentos foram feitos os cálculos usado as Equações 7 a 11, para obter os coeficientes de transferência de calor por convecção e evaporação (hcw e hew, respectivamente), a taxa de transferência de calor por convecção (qcw) e por evaporação (qew), e a produção horária de água destilada (mw). Nas Figuras 13 a 15 se apresenta o comportamento dos coeficientes e das taxas de transferência de calor por evaporação e convecção, calculados para as temperaturas de um dia de inverno e um dia de verão.

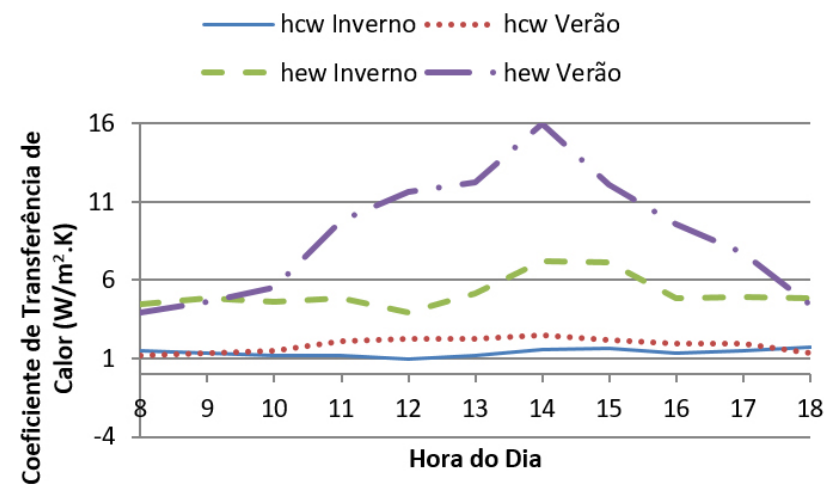

Figura 13. Coeficientes de transferência de calor por convecção e por evaporação versus hora calculado para um dia de inverno e de verão.

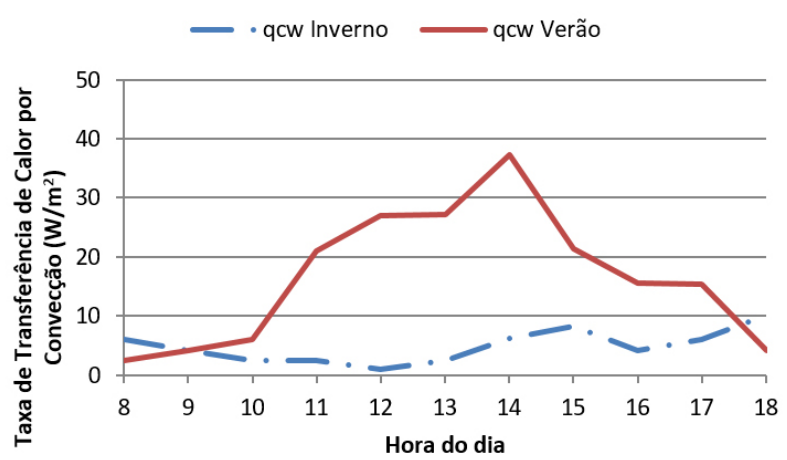

Figura 14. Taxa de transferência de calor por convecção versus hora calculada para um dia de inverno e verão.

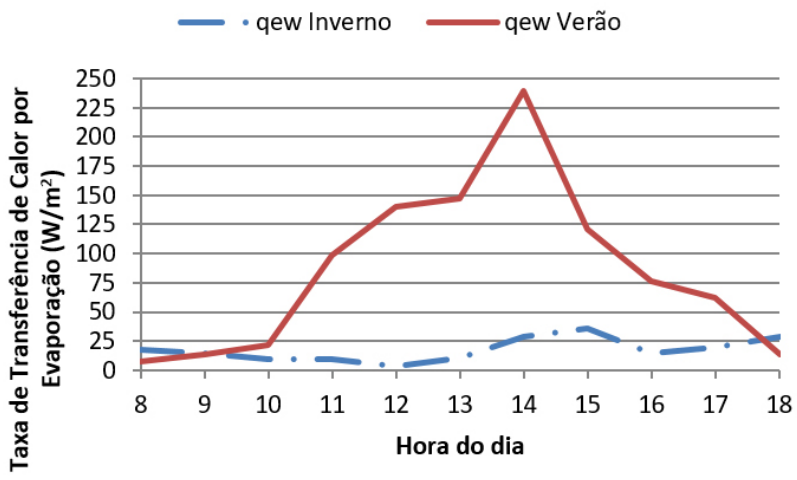

Figura 15. Taxa de transferência de calor por convecção versus hora calculada para um dia de inverno e verão.

Das figuras anteriores pode-se concluir que o coeficiente de transferência de calor de evaporação, e consequentemente, a taxa de transferência de calor por evaporação foram maiores do que o coeficiente de transferência de calor por convecção e sua respectiva taxa, em ambos os dias avaliados. Estes resultados, evidenciam que a principal forma de transferência de calor no destilador solar é devida à evaporação da água. Analisando apenas os coeficientes e as taxas de transferência de calor por convecção (Figuras 13 e 14), no inverno têm-se os maiores valores na primeira e última hora de análise, enquanto que 
das $9 \mathrm{~h}$ às $18 \mathrm{~h}$ os maiores valores são obtidos no verão. Tal fato pode ser explicado pela diferença de temperatura entre Tw e Tg, força motriz do fluxo de calor por convecção. Com relação aos coeficientes e às taxas de transferência de calor por evaporação (Figuras 13 e 15), houve grande aumento no verão durante o período das $9 \mathrm{~h}$ às $18 \mathrm{~h}$ correspondente ao intervalo de maior incidência de radiação, demonstrando a forte dependência da transmissão de calor evaporativo com a temperatura da água.

Por fim, foi possível então prever a produção de água destilada para cada dia em análise a partir da Equação 11, usando as medidas de temperatura $\mathrm{Tw}$ e $\mathrm{Tg}$, e adotando o calor latente de vaporização médio da água dado em $\mathrm{J} / \mathrm{kg}$. Os resultados desses cálculos são apresentados na Figura 16.

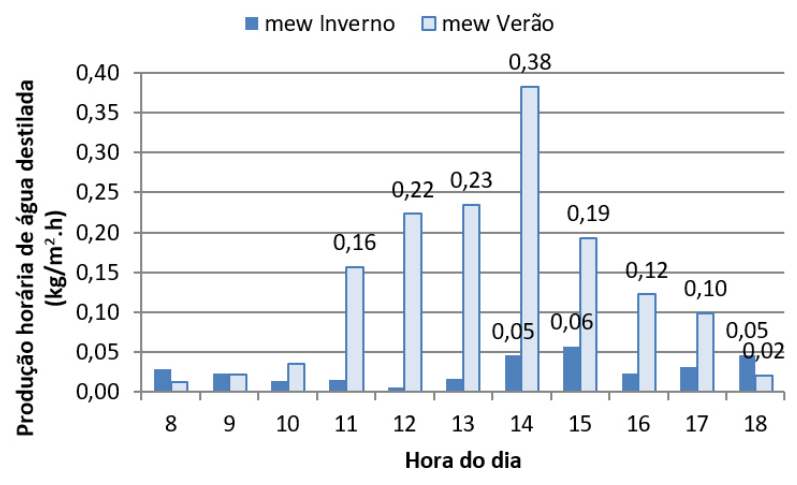

Figura 16. Produção de água destilada em um dia de inverno e verão.

A produção de água destilada no período das $8 \mathrm{~h}$ às $18 \mathrm{~h}$ durante o verão foi substancialmente maior do que no inverno, passando de $0,31 \mathrm{~kg} / \mathrm{m} 2$ para $1,51 \mathrm{~kg} / \mathrm{m} 2$, sendo muito próximos dos valores reportados na literatura para destiladores solares passivos com água salgada14. Sendo que o momento de maior produção foi às $14 \mathrm{~h}$, hora em que foi registrada a maior temperatura da água da bacia, como também a maior variação entre $\mathrm{Tw}$ e $\mathrm{Tg}$, contribuindo para aumento da transmissão de calor por convecção e por evaporação.
A Tabela 3 mostra os valores de eficiência horária de produção de água obtida para o destilador solar para um dia de inverno e um dia de verão. $O$ cálculo da eficiência foi feito usando a Equação 12.

Analisando os dados da Tabela 3 anterior podemos concluir que o rendimento foi muito baixo no dia de inverno, apresentando a eficiência mais altas nas primeiras e últimas horas do dia, onde a incidência da radiação é menor e diminuiu consideravelmente nas horas de maior radiação, devido a que a diferença de temperatura média no dia foi muito pequena, na faixa de 3 a $60 C$, não sendo capaz de compensar o aumento da incidência da radiação sobre a massa de água, fazendo com que a eficiência diminua.

Para os dados coletados no verão, observou-se que já desde as primeiras horas do dia, a diferença de temperatura compensava o aumento da radiação e a eficiência aumentou até um valor máximo de 30,13 às 14 horas, quando começou a diminuir. As 17 horas foi observado um pico de eficiência de 41,33 , que pode ser associado à diminuição da radiação incidente.

Tabela 3. Dados de radiação horária incidente na superfície inclinada (It), taxa de transferência de calor por evaporação (qew) e eficiência do destilador no dia de verão e inverno.

\begin{tabular}{|c|c|c|c|c|c|c|}
\hline \multirow{2}{*}{ Hora } & \multicolumn{2}{|c|}{ I(t) } & \multicolumn{2}{c|}{ qew } & \multicolumn{2}{c|}{ i } \\
\cline { 2 - 7 } & $\mathrm{W} / \mathrm{m} 2$ & $\mathrm{~W} / \mathrm{m} 2$ & $\mathrm{~W} / \mathrm{m} 2$ & $\mathrm{~W} / \mathrm{m} 2$ & $\%$ & $\%$ \\
\cline { 2 - 7 } & $30 / \mathrm{mai}$ & $27 / \mathrm{out}$ & $30 / \mathrm{mai}$ & $27 /$ out & $30 / \mathrm{mai}$ & $27 /$ out \\
\hline 8 & 459,86 & 377,08 & 17,77 & 7,85 & 3,86 & 2,08 \\
\hline 9 & 711,37 & 605,49 & 14,61 & 13,85 & 2,05 & 2,29 \\
\hline 10 & 910,87 & 790,17 & 9,22 & 22,05 & 1,01 & 2,79 \\
\hline 11 & 1043,94 & 909,33 & 9,72 & 98,31 & 0,93 & 10,81 \\
\hline 12 & 1101,64 & 951,04 & 3,96 & 139,76 & 0,36 & 14,70 \\
\hline 13 & 1080,23 & 911,38 & 10,25 & 147,21 & 0,95 & 16,15 \\
\hline 14 & 981,44 & 794,08 & 28,73 & 239,25 & 2,93 & 30,13 \\
\hline 15 & 812,74 & 610,83 & 35,78 & 121,07 & 4,40 & 19,82 \\
\hline 16 & 588,65 & 383,16 & 14,61 & 76,66 & 2,48 & 20,01 \\
\hline 17 & 366,92 & 150,27 & 19,80 & 62,11 & 5,40 & 41,33 \\
\hline
\end{tabular}




\section{Análise da Água Destilada}

A análise da água utilizada para abastecer o destilador apresentou condutividade média de $66,8 \mu \mathrm{S} /$ $\mathrm{cm}$ e resistividade de $0,0150 \mathrm{M} \Omega . \mathrm{cm}$. Após destilação, os valores de condutividade obtidos nas amostras analisadas foram em média $3,9 \mu \mathrm{S} / \mathrm{cm}$, e a resistividade média de $0,26 \mathrm{M} \Omega . \mathrm{cm}$, sendo que todos os resultados atenderam às especificações da Farmacopeia Brasileira para água Tipo Reagente, que são: 1,0 a $5,0 \mathrm{mS} / \mathrm{cm}$ para a condutividade, e resistividade $>0,2 \mathrm{M} \Omega . \mathrm{cm}$. Amostras de água destilada obtidas nos destiladores de água elétricos, utilizados nos laboratórios da Universidade Federal também foram analisadas e apresentaram condutividade média de 3,0 $\mu \mathrm{S} /$ $\mathrm{cm}$ e resistividade de $0,33 \mathrm{M} \Omega . \mathrm{cm}$.

Após um mês de uso sem limpeza do equipamento, amostras da água da bacia do destilador foram coletadas para análise e o valor médio de condutividade obtido foi de 102,4 $\mu \mathrm{S} / \mathrm{cm}$ e resistividade de $0,0098 \mathrm{M} \Omega$.cm. Porém, mesmo com o aumento da concentração de impurezas na água da bacia, os valores de condutividade e resistividade das amostras de água destilada produzidas permaneceram dentro do padrão.

\section{Conclusões}

O uso do modelo ambiental de Duffie e Beckman24 para o cálculo da radiação permitiu concluir que o ângulo de inclinação da cobertura ideal para o destilador solar de água, para ser instalado na cidade de Goiânia, é de 20o, muito próximo à latitude local. A radiação incidente local varia durante o ano na cidade de Goiânia é alta e permite o aproveitamento da energia solar para o fim desejado.

O coeficiente e a taxa de transferência de calor por evaporação são as principais formas de transmissão de calor dentro do destilador solar de água, e estes dependem do valor da temperatura da água na bacia e consequentemente da radiação incidente.

O coeficiente e a taxa de transferência de calor por convecção contribuem para a produção da água, mas não são as determinantes e dependem da diferença de temperatura entre a água da bacia e a parte interna da cobertura do destilador.
A temperatura ambiente não afeta os coeficientes e as taxas de transferência de calor por convecção e evaporação. A produção de água destilada foi maior no verão do que no inverno, o que pode ser relacionado com os valores de radiação solar incidente e a diferença entre a temperatura da água e da parte interna da cobertura. Os valores de produção obtidos foram similares aos reportados na literatura para destiladores solares passivos.

A eficiência do destilador solar foi significativamente maior no teste do mês de verão do que no do inverno, o que foi atribuído a diferença na radiação incidente nas diferentes estações do ano. A água destilada obtida no equipamento atende aos parâmetros da Farmacopeia Brasileira para água Tipo Reagente, sendo assim, pode ser usada para substituir a água destilada obtida nos destiladores elétricos.

\section{Referências}

1. Morrison, J., Morikawa, M., Murphy, M., \& Schulte, P. (2009). Water Scarcity \& Climate Change: Growing Risks for Businesses \& Investors. Ceres, Pacific Institute.

2. K. Sampathkumar, T.V. Arjunan, P. Pitchandi, P. Senthilkumar; Active solar distillation-A detailed review; Renewable and Sustainable Energy Reviews 14 (2010) 1503-1526

3. Tiwari, G. N., Singh, H. N., \& Tripathi, R. (2003). Present Status of Solar Distillation. Solar Energy, 75, 367-373.

4. Duffie, J., \& Beckman, W. (1991). Solar Engineering of Thermal Processes (2. ${ }^{\mathrm{a}}$ ed.). New York: John Wiley and Sons.

5. Adel M. Abdel Dayem; Experimental and numerical performance of a multi- effect condensation-evaporation solar water distillation system; Energy 31 (2006) 2710-2727

6. Peter Wassouf, Tom Peska, Randeep Singh, Aliakbar Akbarzadeh; Novel and low cost designs of portable solar stills; Desalination 276 (2011) 294-302

7. Hikmet S. Aybar, Fuat Egeliofglu, U. Atikol; An experimental study on an inclined solar water distillation system; Desalination 180 (2005) 285-289

8. Emrah Deniz; An Investigation of Some of the Parameters Involved in Inclined Solar Distillation Systems; Environmental Progress \& Sustainable Energy (Vol.32, No.2), 2013

9. Imad Al-Hayek, Omar O. Badran; The effect of using different designs of solar stills on water distillation; Desalination 169 (2004) 121-127 
10. A. Hanson, W. Zachritz, K. Stevens, L. Mimbela, R. Polka d, L. Cisneros; Distillate water quality of a single-basin solar still: laboratory and field studies; Solar Energy 76 (2004) 635-645

11. R. Saidura, E.T. Elcevvadia, S. Mekhilefb, A. Safari b, H.A. Mohammed; An overview of different distillation methods for small scale applications; Renewable and Sustainable Energy Reviews 15 (2011) 4756- 4764

12. Iyad M. Muslih, Salan M. Abdallah, and Wafa Abu Husain; Cost Comparative Study for New Water Distillation Techniques by Solar Energy Using; Applied Solar Energy, 2010, Vol. 46, No. 1, pp. 8-12.

13. Rai, S. N., \& Tiwari, G. N. (1982). Single Basin Solar Still Coupled with Flat Plate Collector. Journal of Energy Conversion and Management, 23, 145-150.

14. Tiwari, G. N., Dimri, V, \& Chel, A. (2009). Parametric Study of an Active and Passive Solar Distillation System: Energy and Exergy Analysis. Desalination, 242, 1-18.

15. A. E1-Bahi, D. Inan; A solar still with minimum inclination, coupled to an outside condenser; Desalination 123 (1999) 79-83

16. B. Tleimat, B., \& Tleimat, M. (1993). Developments in Saline Water Distillation Technology. Desalination, 93, 293-296.

17. Rajesh Tripathi, G.N. Tiwari; Effect of water depth on intemal heat and mass transfer for active solar distillation; Desalination 173 (2005) 187-200

18. R. Bhardwaj, M.V. ten Kortenaar, R.F.Mudde; Influence of condensation surface on solar distillation; Desalination 326 (2013) 37-45

19. Anil Kr. Tiwari and G. N. Tiwari; Annual performance analysis and thermal modelling of passive solar still for different inclinations of condensing cover; Int. J. Energy Res. 2007; 31:1358-1382

20. A.S. Nafeya, M.A. Mohamadb, M.A. Sharaf; Enhancement of solar water distillation process by surfactant additives; Desalination 220 (2008) 514-523

21. Shailendra Kumar SHUKLA and Ajeet Kumar Rai; Analytical Thermal Modelling Of Double Slope Solar Still By Using Inner Glass Cover Temperature; Thermal Science: Vol. 12 (2008), No. 3, pp. 139-152

22. G. N. Tiwari,y, Vimal Dimri, Usha Singh, Arvind Chel and Bikash Sarkar; Comparative thermal performance evaluation of an active solar distillation system; Int. J. Energy Res. 2007; 31:1465-1482

23. http://gsfotovoltaico.com.br/?page_id=70, Associação Brasileira de Indústria Elétrica e Eletrônica, Mapa de Radiação Solar no Brasil, acessado no dia 28 de maio de $\mathbf{2 0 1 4}$.

24. Duffie, J. A.; Beckman, W. A. Solar Engineering of Thermal Processes $4^{\text {a }}$ edição, 2013. New York: John Wiley and Sons.

25. Dunkle, R.V. Solar Water Distillation: The Roof Type Still and a
Multiple Effect Diffusion Still. 1961. International Heat Transfers Conference, ASME, Part V, University of Colorado, Boulder, 895902,1961.

26. Ghoneyem, A.; Ileri, A. Software to Analyze Solar Stills and an Experimental Study on the Effects of the Cover. Desalination, 1997. 114, p. 37- 44.

27. Jorge, B. M. J. Simulação de Processos de Destilação Solar de Água Salgada, 2011. 103f. Dissertação de Mestrado em Engenharia Mecânica. Universidade Técnica de Lisboa - Portugal.

28. Singh, H.N.; Tiwari, G.N. Monthly Performance of Passive and Active Solar Stills for Different Indian Climatic Conditions. Desalination, 2004. 168, p. 145-150.

29. Pina, A. V. V., Dessalinização solar no abastecimento de água para uma família no arquipélago de Cabo Verde, 2004. Monografia. Universidade Federal do Rio Grande do Sul - RS/Brasil.

30. Bezerra, M. A. S. Desenvolvimento de um destilador solar para tratamento de águas de produção de petróleo com vistas a sua utilização na agricultura e geração de vapor. 2004. 106f. Dissertação de Mestrado em Engenharia Química. Universidade Federal do Rio Grande do Norte, Natal - RN.

31. Murugavel, K. K.; Chockalingam, Kn. K. S. K.; Srithar, K. Progresses in Improving the Effectiveness of the Single Basin Passive Solar Still. Desalination, 2008. 220, p. 677-686.

32. Instituto Nacional de Meteorologia - INMET

33. Dimri, V. et al., Effect of condensing cover material on yield of an active solar still: an experimental validation. Desalination v. 227 (2008), p. 178-189

\section{Camila T. Damasceno, Gustavo R. Jordão \& Caridad N. Pérez}

Universidade Federal de Goiás, 74001-970, Goiânia, Goiás, Brasil. *E-mail: carynoda@gmail.com 